\title{
Experiences of first-generation scholars at a highly selective UK university
}

Caitlin Hindle, Vikki Boliver, Ann Maclarnon, Cheryl McEwan, Bob Simpson and Hannah Brown

\begin{abstract}
Targets set by the UK Office for Students require highly academically selective UK universities to enrol a greater percentage of students identified as least likely to participate in higher education. Such students are typically at a disadvantage in terms of levels of academic preparedness and economic, cultural and social capital. Drawing on eighteen interviews with first-generation students at Durham University, we identify five sites of pressure: developing a sense of belonging within the terms of an elite university culture, engagement in student social activities, financial worries, concerns about academic progress, and self-transformation. Based on these insights, we argue that support for first-generation scholars will require that universities recognise and redress elitist cultures that discourage applications from prospective first-generation scholars and prevent those who do enrol from having the best educational and all-round experience.
\end{abstract}

\section{KEYWORDS}

first-generation scholars, higher education, highly selective universities, inclusion, widening participation, United Kingdom

'First-generation scholars' is a term often used to refer to students whose parents do not have a university degree, but also more expansively to mean students from a wide range of 'non-traditional' backgrounds. ${ }^{1}$ Such students are significantly underrepresented in UK higher education (Henderson et al. 2019), especially among students attending the UK's most academically selective universities (Boliver 2015; Sutton Trust 2000, 2007). The UK's Office for Students (OfS) recently announced ambitious targets to tackle such inequalities by requiring 'higher-tariff universities' (research-intensive universities with stringent entry requirements) to develop actionable plans to reduce 
current socioeconomic and ethnic gaps in access, success and progression. Many of the UKs highly selective universities will have to do significant work to meet the OfS target, and Durham University, where our study is based, is no exception. Participation in higher education varies across the UK, with the north-east of England, where Durham University is based, having one of the lowest overall participation rates. Participation also varies significantly within regions and has a strong correlation with economic affluence (Department of Education 2018). In order to widen access, the OfS requires UK Universities to reduce the ratio of entrants from high as compared to low HE (higher education) participation areas $^{2}$ to $3: 1$ by $2021-22$ and to perfect equity by 2038-39 (OfS 2018). Currently, the ratio for Durham University stands at 10:1 overall, with figures varying significantly across departments.

Like many other institutions, Durham University's plan to address inequities in access consists of radically rethinking the basis on which students are admitted to university and a range of outreach activities that seek to encourage students from low participation neighbourhoods to apply to the university (University of Durham 2019). These goals are commendable, but they raise questions about how well students who are least likely to attend university can settle into academic life and to what extent highly selective universities can offer these students the chance to thrive, both in intellectual and social terms. In order to attract students of diverse backgrounds to highly selective universities in the first place, there is a need to do more to ensure that universities are welcoming and inclusive environments for people of diverse backgrounds.

The existing literature on first-generation scholars and those from other under-represented groups has underlined a number of common findings that reflect issues of identity, transition from school to university and student experiences and learning outcomes. A number of studies have argued that for a student to be successful at university, they need to master the higher education student 'role' (Collier and Morgan 2008: 425). This can be harder for first-generation scholars who, in addition to being less well-resourced financially than students from more advantaged backgrounds, tend to lack the cultural and social 'capitals' (Bourdieu 1986) that facilitate the transmission of 'know-how' required to adjust to higher education. Cultural capital implies a degree of familiarity with the dominant culture (Bills 2003), which at selfdefining elite universities is overwhelmingly middle-class or upper-class and white (Reay, David et al. 2005: 10), while social capital includes the existence and development of beneficial relationships with fellow students and 
staff (Pascarella et al. 2004). Students from middle-class backgrounds tend to find the transition to higher education easier than those from workingclass backgrounds because they often begin with higher levels of academic competence, are more confident, and feel a greater sense of entitlement to be at university (Reay, David et al. 2005). In contrast, first-generation scholars and working-class students are more likely to experience setbacks in their learning and social integration at university, which has been linked to a sense of conflict between the student's identity and the dominant culture of the institution (Byrom and Lightfoot 2012).

Students from first-generation and working-class backgrounds can also experience a range of other challenges relating to their family backgrounds and relationships with people at 'home'. First-generation students are more likely to come from low-income, working-class families (Terenzini et al. 1996). They are also more likely to have family or home responsibilities that they must manage alongside their education, and more commonly work full- or part-time during their degrees. These factors can all contribute to achieving lower grades (Pascarella et al. 2004). Meanwhile, friends and family members may be unfamiliar or uncomfortable with the idea of university, which can cause conflict or a sense of disassociation from people to whom students were close before attending university (Byrom and Lightfoot 2012; Pike and Kuh 2005). The struggle of juggling work, family, and university relationships can cause psychological strain (Reay, Crozier et al. 2010). Given these facts, it is not surprising that first-generation scholars are less likely to complete their degrees (Choy 2001; Ishitani 2003, 2006; National Center for Education Statistics 2002) particularly when they come from working-class backgrounds (Thayer 2000).

The experiences of first-generation scholars have sometimes been framed using a deficit model that casts these students as other and emphasises what they lack relative to students from 'traditional' backgrounds. A deficit approach tends to identify solutions to widening access problems centred on the perceived need for first generation scholars to become more similar to their more advantaged peers, not only economically but also culturally. This may entail plainly inaccurate assumptions of cultural deficit, as with the centring of much university outreach work around the now-debunked assumption that those from 'non-traditional' backgrounds have lower aspirations than 'traditional' students (Harrison 2018). Alternatively, it may entail normatively driven assumptions about what it means to 'fit in' at university, which place the onus on first-generation scholars to adapt to the dominant 
culture, rather than attempting to change the culture to embrace a variety of students.

This study explores these issues through findings from in-depth interviews with eighteen students in their second year of undergraduate study at Durham who identified themselves as the first in their family to attend university. We use our findings to make recommendations to improve support for first-generation scholars attending highly selective universities and to highlight the importance of mainstreaming inclusion throughout the student learning experience, not only at the point of admission. Our findings suggest that highly selective institutions like Durham are unlikely to meet new targets for participation without integrated support measures and strategies to improve experiences for students from groups least likely to attend university. Crucially this requires recognition and redress of the exclusionary cultures that frequently characterise self-defined elite universities.

\section{Methods}

We carried out semi-structured interviews to explore the experiences of students who self-identified as the first in their family to attend university. Participants were studying a range of different academic subjects and all were in the second year of their degree programme at Durham University. Founded in 1832, Durham University is one of the UK's oldest universities and a member of the Russell Group of self-identifying 'elite' UK universities. Students were recruited via the University's colleges - sixteen distinctive bodies to which all students belong throughout their degrees. Whether the student is resident in their college or 'living out', each college purports to offer students 'a sense of community and belonging. The colleges sent emails to students on behalf of the researchers inviting them to participate in the study. We aimed to recruit twenty participants for the project, equally split between men and women. Because there is a perception at Durham University of a cultural distinction between 'Hill' colleges located outside of the city centre in modern accommodation and 'Bailey' colleges located within the historic centre of Durham's World Heritage site, we also aimed to recruit representative numbers of students from each 'type' of college. Some colleges were reluctant to help with recruitment, but most engaged with the study. We found it harder to recruit men than women. We eventually recruited 18 participants -12 females and 6 males - 7 from the six 'Bailey' colleges and 11 from the ten 'Hill' colleges. Of our research participants, 83 per cent were state-school educated and 83 
per cent identified as working-class; in contrast, 63 per cent of the wider cohort of Durham students were educated at state schools and the University has the sixth lowest state-school intake in the country (HESA 2018a, 2018b). Of these eighteen students, eight had come to the university via widening participation schemes. ${ }^{3}$

The interviews were carried out by the lead author, a recent Durham University graduate and first-generation scholar, supported by a project steering group that included four students who identified as first-generation scholars who were not among our research participants as well as five members of staff from three departments and one college. The steering group gave regular input during the research process, notably at the point of study and recruitment design, in developing interview questions, and in data analysis. The average length of the interviews was forty-five minutes and all interviews were transcribed verbatim. The transcriptions were anonymised and analysed thematically as outlined by Virginia Braun and Victoria Clarke (2006).

\section{Results and discussion}

Five main themes emerged from our analysis of the interviews: experiences of achieving a sense of belonging in the context of assumptions about the University's reputation and 'culture'; engagement in student social activities; financial worries; academic progress, and self-transformation. Overall, our respondents understood their first-generation identity to have had a significant negative impact on their experience of university, with the most concerning issues around what some students perceived to be a 'battle' with a dominant university culture of privilege, pressure and high achievement from which they felt excluded. This culture is formed and perpetuated by the dominance of students at the university who are mostly white, male, involved in sports, and who engage in 'lad culture'. Overall, students from non-working-class backgrounds in our sample had fewer criticisms about their university experiences and felt the transition to higher education was easier than those who identified as working class, suggesting not only the need for better support but also a radical shift towards a more inclusive university culture.

\section{University reputation and culture}

Durham University is often associated with elitism and a demographic of white, middle-class students particularly within local communities in the 
surrounding deindustrialised and economically deprived region, but also among some members of the university community. Most of our research participants had preconceptions that the institution was not well-suited for socioeconomically disadvantaged students. Working-class students perceived Durham as having a culture of privilege and high achievement that could be off-putting.

As I got older, I started realising, like, the kind of institute it is, if you know what I mean, like people from my kind of background don't usually go here. (Male_Bailey_8, working-class, state-educated)

I was worried I might not fit in.

(Female_Hill_15, working class, state-educated)

When asked to elaborate on the 'culture' of Durham University the responses were mostly negative:

Elitist ... in my head elitism has connotations of exclusion, not giving fair opportunities for those who haven't been able to make it themselves. (Male_Bailey_8, working-class, state-educated)

There's a massive, major middle-class vibe in Durham . . . you basically just have carbon copies of the same people, you know, everyone even wears the same stuff, like, it's not a very individual place.

(Female_Hill_13, working-class, privately educated)

Families and friends of first-generation scholars sometimes discouraged them from applying to self-defining elite universities because of their reputation as middle-class spaces.

My sister and my boyfriend at the time actually didn't want me to go to Durham University because they thought it wasn't the right kind of place for me because it's so middle upper-class heavy.

(Female_Bailey_1, working-class, state-educated)

Other students were discouraged from applying to university at all, echoing findings in the literature that have shown that whilst in middle-class families going to university is often an unspoken expectation, in workingclass families the decision can clash with family values (Allatt 1996).

They [parents] wanted me to not go to university [and] rather do an apprenticeship. (Female_Bailey_7, working-class, state-educated) 
I know my dad thinks the whole thing's a waste of time, and I'm here for three years of glorified partying.

(Female_Bailey_17, working-class, state-educated)

Responses from participants also focused heavily on the 'type' of students that they perceived to be representative of Durham: white and middle-class. For example, one student stated that Durham has 'a middle-class culture and a middle-class feel, like university itself is a middle-class institution'. (Female_Hill_15)

However, for most of the students, the negative perceptions of the university had not been a deterrent for applying because they also associated the reputation of Durham with success and achievement, further supporting the argument that assumptions of an aspirational deficit among working-class students are false. Our interviewees were particularly concerned about their future entry into a competitive job market. According to one student,

It's been pushed in the last fifteen years to go to university, that's the new benchmark, if you don't have a degree then you're going to be working a ... not-so-good job. (Male_Bailey_6)

Perceived benefits encouraged first-generation scholars to enrol in university despite discouragements from family and friends.

Sometimes I question, 'Oh, should I have gone to this Uni?' but . . . this is the best place for career opportunities for you to have a life that you never particularly had [before]. (Female_Bailey_1, working class, state-educated)

Within discussions about university 'culture', many of the participants believed that the negative culture at Durham was exacerbated by prejudice against certain groups and 'lad culture'.

The culture [here] is so intensely ingrained in whiteness, ingrained in masculinity, and I think, toxic masculinity.

(Female_Bailey_1, working-class, state-educated)

[When I came to Durham, I encountered] some views and behaviour I wasn't expecting to come across ... it's not okay to be racist or sexist or misogynistic ... Drinking culture, 'lad culture', class culture, race culture, gender culture, ... that needs some work, that needs changing, [that's] the thing that I find so disgusting every time.

(Female_Hill_3, middle-class, privately educated) 
For some students, perceptions of Durham culture being different to their own led to feelings of social isolation. This was intensified by the feeling among some respondents that they were engaged in a higher stakes activity in their choice to attend university than others around them whom they imagined to have relatively unlimited funds because of their high-spending and constant socialising.

Some of the other students live in a weird bubble with this massive safety net.... If I fail this, I've got a lot of debt and no degree, no potential career.

(Male_Bailey_6, working-class, state-educated)

I think it's more the culture of having money that I've been excluded from ... it can create quite a barrier in friendship if you can't really relate to each other, especially if the friends you have don't take into consideration that you might not be willing to spend as much money or have a stigma attached to spending money.

(Male_Bailey_8, working-class, state-educated)

The dominant white, middle-class culture at Durham University is reinforced alongside the facilitation of 'lad culture' and toxic masculinity perpetuated in sports and societies, drinking, socials and other aspects of university life. Many first-generation scholars battle with the knowledge they are unlikely to 'fit in' whilst also seeing attending a highly selective university as a necessary vehicle to a successful career. Unfortunately, this often leads to feelings of isolation and adds additional pressure to many first-generation scholars attending university.

\section{Sports and Societies}

Participation in extracurricular activities is considered helpful for a student's successful transition to higher education (Inkelas et al. 2007), and yet prior research has found first generation scholars and students from disadvantaged backgrounds are much less likely to engage in sports, societies and other activities (Monaghan 2018; Pascarella et al. 2004). At Durham University where sports teams and student societies are a central element of the extracurricular provision of Colleges and the wider University, some of our participants found these spaces welcoming and central to their enjoyment of university, while others found them alienating. Some contrasted themselves with more privileged students whom they felt had received 'training' to excel in a sport 
or talent. A sense of exposure to ultra-smart, ultra-talented people led some respondents to experience a lack of confidence,

I did have a really tough time last year with adapting to societies and the constantly being around people who do, like, five different extracurricular activities ... it's almost like an unattainable kind of . . . different world. (Female_Bailey_1, working-class, state-educated)

You're almost expected to be amazing at sports, a language, you have to be doing all these extracurricular activities and all these firm talks and stuff ... If you're not doing stuff, people almost look down at you, like, 'oh, they're only doing their degree'.

(Female_Bailey_7, working-class, state-educated)

When I'm in Durham I feel like everyone's better than me, and I feel less confident. (Female_Hill_11, working-class, state-educated)

Durham University is renowned for its high sporting performance that it celebrates as central to its culture and student experience. Many students, especially those from private schools, attend Durham University partly to continue practising sports at a high level. Among our respondents, Female Bailey_7 chose to attend Durham over Oxford because of the reputation of the Durham Women's Rugby team. Another participant described how she found the rugby team supportive:

I arrived for preseason rugby. The club really prides itself on having that good academic support network of older girls as well as from the social point of view. When you're on the bus on the way to games, when I'm typing up work, they'll read through my essays.

(Female_Hill_14, working-class, state-educated)

Other sports teams did not have the same positive reputation, and some were seen as perpetuating troubling aspects of the 'Durham culture' that were considered unwelcoming by many first-generation scholars, especially when it came to drinking and participating in 'socials'. 'Socials' were thought to foster 'lad culture', classism, and exclusion.

I play quite a lot of college football and seeing members of college football, like, the way that lad culture formulates is absolutely appalling. (Male_Hill_9, working-class, state-educated) 
Like the darts women's college team, I was like, 'Oh it looks fun I'll try', but my friends were like, 'No you don't want to it's like really cliquey, ... . it's the girls who went to, like, London private schools where they all know each other and if you're not from a London private school they kind of, like, shut you out. (Female_Hill_15, working-class, state-educated)

Amongst our participants, only 50 per cent had joined a sport or student society in their first year, compared to over 85 per cent of Durham students as a whole. ${ }^{4}$ Amongst our participants, sporting engagement had been relatively uncommon at their schools, especially at state schools where some described a division between those who excelled at academic study and those who excelled at sports. Others came to Durham without prior experience of some of the sports that were popular at the university, such as rowing and lacrosse. As one male student put it, 'A lot of the societies and stuff at my college specifically were what I see as public-school sports' (Male_Bailey_8). For these students, mixing with other students who were talented both academically and athletically made them lack confidence about their own achievements. Lack of prior experience also sometimes discouraged them from joining sports or societies and led them to miss out, which many participants later regretted.

I had the mind-set that, like, you either did sports and physical stuff or you were into academics, so when I came here and I saw people who were good at both it, was sort of revolutionary for me.

(Male_Hill_2, working-class, state-educated)

I sometimes feel a bit excluded, but especially the sport thing because there weren't any sports teams in my sixth form so I never considered doing sport ... I was like, 'Oh, of course I'm not going to join rowing, I've never rowed', because I didn't realise that you could just start it new.

(Female_Hill_11, working-class, state-educated)

The idea that students at Durham University must excel both academically and athletically or in their chosen extracurricular activity is often a very intimidating concept for working-class first-generation students. Those students who had attended schools that prioritised either athletic or academic achievement but did not expect students to excel in both often felt the pressure more than others. Many were afraid or reluctant to participate at all despite awareness that participation in extracurricular groups was necessary for assimilation into university life. 


\section{Alcohol consumption}

From the perspective of our respondents, a significant part of the 'culture' they experienced at Durham involved excessive drinking, particularly inside sports and societies. Sports teams and societies usually conducted weekly socials, which could mean that students were going out four or more nights a week. This was extremely alienating for some groups of students, especially those who did not have the same finances as their friends. According to one, 'Apart from drinking, there's very little to do in Durham' (Male_Bailey_8). Our respondents often assumed that more privileged students could afford to socialise more often.

It was a shock to the system . . . I don't drink or go out or anything like that, so freshers' week was just madness, and I felt very overwhelmed because I was like, 'Oh, am I in the right place!?', because . . . so many people are, like, drunk and going out all the time ... I I felt quite alone.

(Female_Hill_10, working-class, state-educated)

I didn't want to go out and get smashed every single night so I wasn't necessarily as included. (Female_Hill_13, working-class, privately educated)

\section{Other student events}

Durham colleges have regular 'formals', communal dinners often requiring academic gowns. Some colleges have strict dress codes for these events, for example requiring 'ladies . . . [to] wear a cocktail dress or trouser suit [and] gentlemen to wear a lounge suit with a necktie. ${ }^{5}$ Colleges, societies, and some departments also have less frequent 'balls', where a three-course meal is followed by music, dancing, and sometimes other activities. These events can cost in excess of $£ 100$ and are frequently in addition to fees paid for basic membership of a College or society. Such costs and the requirement to wear special clothes can make them prohibitive for disadvantaged groups. However, at the same time, many first-generation scholars valued opportunities to experience something new, making their overall experience of these events ambivalent.

I just thought it [Bailey Ball] was such a good experience and something I'd never really experienced before, because a ball is . . . sort of has connotations of 'wow, it's so prestigious and upper-class and I'm not used to this'. (Female_Bailey_4, working-class, state-educated) 
I feel like the balls are pretty cool, like, we all hate them, but secretly we don't ... I hate the idea that I'm basically in a cult here. I'm in a middleclass cult; that's what I've joined.

(Female_Hill_12, working-class, state-educated)

Other participants felt more strongly about the negative dimensions of this aspect of Durham culture. They actively disengaged and felt uncomfortable with events and activities at Durham they viewed as perpetuating elitism, privilege, and exclusion.

I don't enjoy formals at all. It's weird. It doesn't seem like an enjoyable time ... it's a dinner you can't stand up at, banging spoons, doing prayers in Latin . . . all these weird, sort of, quirky, sort of, privately educated things in life. (Male_Bailey_6, working-class, state-educated)

They're [formals] not my gig . . . they're quite pretentious, and they're a shock. It's definitely a shock culture, and I'm not normalised by it. And I don't like it. (Male_Hill_9, working-class, state-educated)

There are societies and clubs that exist on the perimeters of the Durham 'culture'. These 'outsider groups' such as the Mature Student's Association, the Working-Class Association, and the Northern Society are not necessarily part of, or representative of, the dominant culture of Durham University. However, their existence is positive proof of underrepresented groups of students coming together. Male_Bailey_8 acknowledged these fringe societies he was part of by saying, 'there is a culture within that, a culture of defiance, of going against the grain of proving people wrong. And I think that's beautiful'. These groups can be empowering for those who feel excluded from the dominant culture of Durham. ${ }^{6}$

\section{Finance}

For many of the students we interviewed, the financial implications of being at Durham and the costs of a university lifestyle, defined by sports, societies, and drinking, caused major worries and left them with a sense of exclusion. Durham's collegiate system has a number of hidden financial obligations, with formal dinner tickets and Junior Common Room (JCR) memberships (i.e., student college membership fees charged in addition to accommodation fees). These often cost over $£ 100$ a year. Playing sports can also involve equipment costs and weekly 'subs'. This puts some students at a disadvan- 
tage and can prevent students from participating altogether. Some students experienced a lack of sensitivity from university staff and other students towards their inability to pay these sums. For students who were already struggling to pay higher than average accommodation fees at Durham, JCR memberships or formal dinner tickets were seen to be the lowest priority, meaning that students who struggled to pay felt unable to participate in college life.

Straight away there was a financial obligation and I think there was the expectation and the assumption that you could afford that straight away. (Female_Bailey_1, working-class, state-educated)

I didn't go to our college ball last year because I couldn't afford the tickets ... I couldn't afford like a suit or anything for it.

(Male_Hill_2, working-class, state-educated)

I feel like freshers' you want to go out, and people around you want to go out and do stuff . . . it's not that I don't want to do those things; it's that I don't want to put any more financial pressure on my Dad.

(Female_Bailey_4, working class, state-educated)

June ball was crazily expensive ... 130 pound not including wine.

(Female_Bailey_18, working-class, state-educated)

The costs of university, both financial (in terms of levels of debt after graduation) and personal, can be great for first-generation scholars, which often makes the transition to university more complex and difficult (Archer and Hutchings 2001). Out of all the students we interviewed, 56 per cent had run into financial problems at Durham University. According to the consumer group Which?, the average annual expenditure for students at Durham is $£ 10,560,{ }^{7}$ yet the maximum maintenance loan is only $£ 9,203 .{ }^{8}$ Non-repayable grants and bursaries have a positive effect on student retention, engagement and success (Hochstein and Butler 1983; Hordósy and Clark 2018). Of our participants, 44 per cent received some form of non-repayable grant or scholarship from the university.

The Supported Progression bursary. ${ }^{9}$ That helps out a lot and without that, I don't even think I would be able to come to university. (Male_Hill_2, working-class, state-educated)

I wouldn't be here if it weren't for my bursary. (Male_Bailey_8, working-class, state-educated) 
Paying for accommodation and living expenses caused financial problems for most participants and consumed the majority of their loans, grants and bursaries. The summer period, when students often have to pay for rent without living in the properties and without receiving student loans, was often particularly tricky and stressful for students. Even with a bursary, grant or loan, many participants still had to borrow money from family members to be able to pay rent or living expenses

Last year was a mess, my student finance didn't cover my accommodation, so my Dad had to add a couple hundred quid each term, which barely covered accommodation. (Female_Bailey_4, working-class, state-educated) I saved up like two and a half, three thousand pounds from working at Boots . . . if I didn't have that last year, I would have died, because it's like seven thousand and something atrocious to live in college, which is not worth it. (Male_Hill_9, state-school educated, working-class)

Our deposit for our house-well, flat-next year was 581 pounds, and I couldn't get that straight away. Like, we nearly lost the house because I couldn't get 581 pounds the next day.

(Female_Bailey_17, working-class, state-educated)

To support the financial costs of being at Durham University, many disadvantaged students take up jobs. Of our participants, 67 per cent had a part-time job while they were at university and many also worked during university vacation periods.

Over the summer was the worst actual part, because obviously we had rent to pay without maintenance loans or anything to help us. So I ended up working night shifts at Lloyds cleaning . . That completely ruined my mental health. (Male_Bailey_8, working-class, state-educated)

Over the summer I had to work for three months, like, just to support the fact that I was paying $£ 300$ of rent . . . you're paying even though you're not living in the property. (Male_Hill_9, working-class, state-educated)

The University recommends that no student work more than twelve hours a week at a part-time job, however many students we interviewed worked more than this recommended maximum. Part-time work of any kind has been found to adversely affect retention, academic involvement and satisfaction with academic performance, social integration, and well-being (Curtis 
and Shani 2009). This can create additional disadvantage in field-based disciplines where students undertake fieldwork for their dissertation in the summer break between their second and third years.

I work at Pizza Express . . . between three and four times a week ... if I've got a talk or an essay due, and I'm like, 'I need this night off', and they're like, 'well, we'll see what we can do.' And it does get difficult. (Female_Hill_12, working-class, state-educated)

I've had to get a job so I work part time as well, and even still, it's so difficult. ... It's quite hard being around such affluent people and trying to keep up with them and trying to act like you're no different than anyone else around you. So I think that puts a lot of financial strain.

(Female_Bailey_17, working class, state-educated)

The costs involved with attending Durham University are substantial and it is not uncommon for students to be unable to cover their necessary expenditure such as rent, bills, and food costs with their maintenance loan alone. Fees do not include the financial costs of participation such as Junior Common Room fees, 'formal' tickets and drinks at socials - participation considered necessary for student retention. Students from lower income backgrounds often depend on bursaries and grants to cover their necessary fees or they take up part-time jobs. The time spent at their jobs ultimately diverts students from working towards their degree.

\section{Academic life}

As a self-defining elite university, Durham places high value on academic achievement. Our participants perceived themselves as being at a disadvantage in terms of transitioning to this academic culture, compared to others they viewed as having received more support at school. One privately educated student we interviewed described her school as,

A very high-pressure environment ... . everyone was working super hard all the time; it wasn't uncool to be in the library. Everyone was of that same mentality that they wanted to do really well ... My school were very on it with getting us talking about UCAS ${ }^{10} \ldots$ we had, like, a UCAS referee ... We had a lot of classes they offered for the entrance tests . . classes after school every week for two hours where he would explain what they're looking for. (Female_Hill_3, middle-class, privately educated) 
Students who did not receive this kind of support were aware that other students had been 'trained' to attend elite universities, unlike themselves. Some had attended schools where staff did not know how to support or encourage their students to enrol in elite universities. This difference of experience perpetuated the inequalities experienced by some of our respondents:

For secondary school, it was more like trying to get people just to pass and get $5 \mathrm{~A}^{*}$ to Cs ... There wasn't a push to go to a high-level university. (Female_Bailey_7, working-class, state-educated)

The students we interviewed thought that their academic disadvantages left them more prone to experiencing stress. As one male student put it, 'Burnout is such an issue'. Others also commented on the stress of academic life:

I thought I would enjoy it [university] more than I am. I think because I'm just so stressed about work all the time, even though I do so much.

(Female_Hill_10, working-class, state-educated)

I feel like I burned myself out at the start because I felt like, 'I'm here I have so much I have to do'. (Female_Hill_12, working-class, state-educated)

Many of our participants assumed that they were struggling more than other students with the transition to university. At Durham, as in other UK universities, there is an expectation that student work is self-led, encouraging independent learning. This means students are expected to reach out for support. For some of the students we interviewed, this system meant they missed out on opportunities, due to lack of confidence or misunderstanding. Our respondents often felt that they lacked understanding of general university procedures and had poor relationships with staff. Sometimes they felt that lecturers assumed everyone who had been given a place at Durham was at the same 'level'.

I think they [Lecturers] think it's a level playing field when it's really not, so, they probably don't take into consideration my educational background family-wise etcetera how many life chances I've had ... They expect me to be the same as everyone else because you've gotten into Durham. (Male_Bailey_8, working-class, state-educated) 
When I was writing my first essay, I was like really, really struggling, didn't know what to do or anything, like, I was like thinking I was just doing it all wrong, like, didn't know how to approach it.

(Female_Hill_11, working-class, state-educated)

The jump to first year from sixth form with very little help or, like, not knowing how to deal with the workload or ask for help . . . like, there's seven readings listed but no one's told me that I only need to do the first one ... Once you're behind, you're behind, you're not going to catch up. And, like, again, I guess, stress, and I was like, 'Oh I can't do this'.

(Female_Hill_15, working-class, state-educated)

Many of the students we interviewed felt as though they had to go through 'extra steps' to get to the same academic level as their more privileged counterparts. This left them with feelings of insecurity and embarrassment.

I've had to go to guest lectures and stuff on how to answer essays, whereas other people would already know that ... I had to go through the extra steps of getting here, I had to go through the extra steps of relearning how to answer things when I got here, and I had to go through the steps of learning how to communicate in a certain way, how to act in a certain way. (Male_Bailey_8, working-class, state-educated)

I spoke to a professor . . . he was just saying in the sort of seminar, 'Oh you know, they really ought to teach you how to take notes when you get to Uni', and I was like, 'Teach me, because I don't know what I'm doing!' ... No one's ever taught me how to take notes, no one's ever taught me how to write an essay. (Female_Hill_13, middle-class, privately educated)

A disparity in experiences of education between middle- and workingclass schools was apparent in the testimonies of different participants. Many working-class students found the effects of the transition to university harder than their middle-class counterparts. They felt less 'trained' for higher education and were more likely to have experienced burn-out and stress. They felt that the University treated them as though all students were equal as soon as they enrolled, but many first-generation participants claimed they had to take extra steps just to learn the 'basics' of university academics and viewed themselves as being at an academic disadvantage compared to their more privileged peers. 


\section{Interactions with staff}

Positive interactions with faculty members are incredibly important for the engagement and satisfaction of all students at university. Especially for firstgeneration scholars, these relationships are imperative for enhancing the student experience (Nettles 1991). Positive contact with faculty members is associated with high levels of integration into university life, which therefore encourages success and persistence in higher education. This is key for retaining students to graduation (Tinto 1987). However, some interviewees viewed interactions with staff at Durham University as either infrequent or negative, an experience that perhaps reflects the emphasis that self-defining elite universities place on being 'research-intensive' rather than 'teachingfocused’ (Boliver, Powell et al. 2018).

I did a French module ... I just wasn't getting it and I had spoken to the teacher and she sort of gave me a, 'well, you did A-levels last year, so you should know this response.' And I thought, 'well, she's not willing to help me, so I'm not going to try'.

(Female_Bailey_4, working-class, state-educated)

I can go from, like, sitting and having a brew with, like, my sociology A-level teacher but here, like, most of the lecturers don't even know my name. (Female_Hill_12, working-class, state-educated)

Feelings of isolation, the belief that they were underachieving, the sense that they should have known better how things worked, or that staff bought into the elitist culture from which they felt excluded put some students off asking for help from teaching staff:

The stigma of needing help when I already thought I wasn't, potentially, in the right university then stopped me probably getting help.

(Female_Bailey_7, working-class, state-educated)

I as a first generational university student, I had an idea that the staff at Durham Uni were enforcing this kind of culture ... I always had in my mind the staff are against me. (Male_Bailey_8, working-class, state-educated)

I know that you could have emailed them [lecturers] or something but people are reluctant to do that because they're like, 'Oh, am I sounding stupid here?' (Female_Hill_15, working-class, state-educated) 
Alongside academic advisors, colleges employ student support staff, and students also run welfare teams in colleges, which students can approach for help. Many students, including first-generation scholars, do not feel comfortable attending student-run welfare sessions, often because they viewed student welfare as being run by the same groups of students who were also excluding them from other activities, but also because of a sense of stigma in not coping with university life that they did not want to share with their peers.

I don't necessarily think I would go to a student welfare person for advice ... I would not want a fellow student in the college, despite their position and despite what they might say, again, I wouldn't necessarily trust them. (Male_Hill_9, working-class, state-educated)

I'd feel a bit weird just chilling, chatting to this student, unloading all my dark, groggy things from the depths of my mind. And then I go to Lloyds [a bar in Durham] and I just see them there.

(Female_Hill_12, working-class, state-educated)

Like participation in sports and societies, good relationships with staff are seen as imperative to student retention. However, the stigma of needing help often stopped first-generation scholars from reaching out and building these important relationships with staff, especially as many students saw the staff as 'not like them' and unwilling to be supportive. This means students were likely to struggle in silence, especially as many students did not feel comfortable going to the student-run welfare team for support either.

\section{Transitions and self-transformation}

Throughout our interviews, respondents expressed ambivalence about the changes and transitions to which life at Durham exposed them. This began during Freshers' Week. Many students commented on feeling overwhelmed at this time by the volume of activities and expectations around drinking and socialising.

The second night, they [older students at college] woke us up at 4 o'clock in the morning with pots and pans to do a one-mile run. They kept on ... [banging on the door of] my room, and I had to shout at someone, which 
is not in my nature, but I was like, 'I'm really sorry but I've got arthritis ... ' Then the next night, at five in the morning, they did a fire alarm test, it was just ... I did not sleep that week. And it was just, again, very overwhelming. (Female_Bailey_1, working-class, state-educated)

I felt very sort of uncomfortable and isolated in the first week. (Male_Hill_2, working-class, state-educated)

I struggled the first, like, week or two ... adapting to a different environment ... I didn't like how cliquey it was from the get-go . . . lots of people just stuck to who they lived near.

(Male_Hill_9, working-class, state-educated)

Those students who identified as working class developed a new awareness of themselves as outsiders at Durham and faced prejudice from some other students.

I think a lot of people don't like to associate with being working class . . . I find that being northern, actually tying that with being first gen, is that you get patronised quite a lot or even like fetishized a tiny bit ... All my friends comment on ... mock what I say.

(Female_Bailey_1, working-class, state-educated)

When they [Castle students] found I went to a comprehensive school, they were like, 'Oh, so you're a comp then?' And I was like, 'I have no idea what that is' . . . being from the North as well, people seem to look down on that as if it was a bad thing, and I'd never experienced that in my life until now. (Female_Bailey_17, working-class, state-educated)

There was also a sense that class-based prejudice was not taken as seriously as other forms of discrimination, partly because of existing equalities legislation:

There's a lot of talk about liberation for LGBT people, ethnic minorities, genders etcetera, and I think that's brilliant and it is inclusive, but they always seem to miss out class, because it's not a protected sort of identity. (Male_Bailey_8, working-class, state-educated)

University is a time of change for most students, but given the exposure to new kinds of culture and the sense held by some of a need to assimilate to this culture in order to succeed, these transformations in relationships and in self can be more extreme for first-generation scholars (Reed-Danahay 2005). 
Some of our participants said they felt a lot more confident when they went home, especially if they were 'breaking the mould' in their hometowns by going to an elite university. However, back at university, some felt less confident as they were comparing themselves with other students. One woman said, 'I feel like when I go home, I'm more confident than I was before, but when I'm in Durham, I'm less confident' (Female_Hill_11).

Most of the participants said that they were more confident and more independent since coming to university. At the beginning of their second year, 67 per cent said they felt more confident and 39 per cent more independent.

I just knew I felt more independent, and I wanted to do my own thing ... I think they [parents] were quite shocked with how independent I'd become. (Female_Bailey_4, working-class, state-educated)

I'm a lot more extroverted than I used to be, I'm more keen to meet people and get out a bit. (Male_Hill_5, working-class, state-educated)

The reasons given for this increase in confidence and independence ranged from learning how to budget, getting a job, succeeding academically and living without parents. Most of the participants viewed these changes as positive.

Previous literature has outlined the expectation that first-generation scholars' relationships with their parents would worsen because the parent's aspirations for their children were not the same as their children's academic aspirations, especially if the parents did not agree with their child going to university. However, only one of the participants felt as though one of her parents was so against her going to university that it affected their relationship. She said:

I think my relationship with my dad has gotten worse since I came to Uni ... he doesn't understand the, like, workload and everything behind it so things like paying for rent, fees, and all the other extra costs that come with it, he is not willing to fund [it]. (Female_Bailey_18).

Notably, this conflict does not necessarily come from the university itself but rather from the added financial burdens that attending university created.

However, most of the participants said that their relationships with people at home had improved since going to university. This may be because attendance at university has become more widely accepted across all social groups. 
I think we [mum and I] get on a lot better as, like, friends, just because I'm not, like, dependent on her anymore.

(Female_Bailey_1, working-class, state-educated)

I think all of my relationships have been improved since going to university and getting away from where I live.

(Female_Hill_10, working-class, state-educated)

However, our respondents often said that they did not feel able to ask their parents for help regarding university experiences, either because they did not want them to worry or they thought their parents would not understand and be able to help.

I take it upon me to sort of leave out something if I know that would cause her [mum] emotional distress.

(Female_Bailey_1, working-class, state-educated)

In terms of my problems at university they [parents] don't really, they can't relate. It's not possible for them to understand.

(Male_Hill_2, working-class, state-educated)

They don't really understand the uni and how it really works. They don't . . . just because they haven’t experienced it; they can't really relate.

(Female_Hill_13, middle-class, privately educated)

Some students commented on how their relationships with their families had become difficult after starting university. Male_Hill_2 suggested that his struggles to become more financially independent had affected how often he could see his family. He also felt as though he could not speak to them about problems at university as they would not understand. Others felt strong pressure to succeed because their families were so proud of them and lacked sources of support when things were not going well because they felt unable to turn to family members for fear of disappointing them.

\section{Conclusions and recommendations}

Academic results for first-generation scholars at Durham are usually very good, and there is evidence from across the sector that these students often outperform their more advantaged peers (Boliver, Gorard et al. 2021; Crawford 2014). However, despite their academic success, our evidence suggests that for a significant number of first-generation scholars their experience at 
Durham is of surviving rather than thriving. These findings are sobering. A third of our participants explicitly said they had felt as though they might have achieved more and felt more comfortable at a different university, and many claimed they were suffering with poor mental health at university. However, our research also offers some suggestions of ways to improve support for first-generation and working-class students at highly selective universities. First and foremost, universities need to recognise that they may be perpetuating ideas of elitism and forms of 'university culture' that make some students feel excluded. Some highly selective universities - including in the past, Durham - have traded on their self-defined elite status in order to attract students (Boliver, Powell et al. 2018). This risks an institution becoming popularly perceived not as 'elite' but rather elitist, 'traditional' and highstatus, and therefore primarily attracting students who associate themselves with these same values. When universities trade on ideas of exclusivity, tradition, esteem and distinction, rather than, or to the exclusion of, values of facilitation, equality and merit, they are promoting values that feel exclusionary for many first-generation scholars and can discourage applications.

Promoting an inclusive culture at some institutions is also likely to require a recognition that experiences of class, accent and regional prejudice are common for a sizable minority of students, as sadly was the case for many of the students we interviewed. Mechanisms for 'calling out' such intolerance need to be clearer and universities should develop clear statements underlining that class-based prejudice is as unacceptable as that directed against protected characteristics. Universities must listen to the critiques of students who feel the need to set up supportive societies based on class membership or ethnic background, such as the Working-Class Students' Association at Durham. As seen in media coverage in 2020, Durham University was described as being a toxic environment for northern-English students who were bullied and harassed by other students for their backgrounds (Parveen 2020). The university responded swiftly and withdrew the offered place of one incoming student. These situations must be regarded seriously and urgently. We must challenge and stamp out practices engaged in by some students that exclude and differentiate others whom they see as socially inferior, and change institutional traditions that do so indirectly, such as through social activities with costs that are prohibitive to a significant minority of students, or University societies that fail to welcome novices.

A second key finding is the recognition that students are not on a level playing field once they enrol and support must be offered to students to 
ensure that people from different backgrounds are given equal opportunities to 'navigate successfully the educational pathway' (Murphy and Hicks 2006: 2). This is particularly important at the current moment, given that highly selective universities are diversifying their intake and at the same time trying to reduce gaps in attainment. Our study revealed student finances, clubs and societies, and academic work as sites where first-generation scholars felt that there was particular need for extra support.

However, whilst targeted initiatives can be important, the requirement for these kinds of support is common across the student body. In these instances, the voice of first-generation scholars is a reminder of the needs of all students, acting as a window onto the struggles that many students experience with the transition to University, through the perspectives of those who are among the most likely to feel excluded, isolated and challenged. The support that students need to participate in unfamiliar learning spaces and communities of practice is different from the support that students may need to recognise and challenge the inequalities that shape their experience of University (Chatelain 2018). It is only by confronting wider institutional inequalities that university cultures will change.

Lower income students are known to suffer financially at university compared to higher income students. Non-repayable grants and bursaries are important for increasing participation, access and outcomes, and can also be used for joining clubs and societies (Hordósy and Clark 2018). Our respondents wanted to see accommodation prices reduced and a more effective distribution of bursaries and scholarships to students across the country. The available 'hardship fund' was experienced as unhelpful, partly because the claiming process was complex and students were sometimes left feeling stigmatised by the process of applying, but also because this money was a loan, and many students were frightened about taking on extra debt. ${ }^{11}$

Our findings also indicate that more needs to be done to reduce barriers (financial and otherwise) that prevent students from accessing opportunities available via clubs and societies and to open up more opportunities for novices in particular sports or activities. Edinburgh University recently created a Participation Grant allowing students to apply for up to $£ 100$ to be able to engage in sports and societies to encourage participation and satisfaction (Monaghan 2018). Some of our respondents also thought this would be a good idea, underlining the fact that, even with the maintenance loan, participation costs were still prohibitive for many students. 
In terms of improving inclusion, our respondents were keen that access to university should be made more equitable and suggested that the single most important thing that universities could do to improve inclusion was to recruit a more diverse cohort in the first place. Given that many Black, Asian, and Minority Ethnic students are also first-generation scholars, this demand for equity speaks directly to the intersectional nature of these issues. It was evident that our participants perceived University staff to be part of the dominant culture too, perhaps underestimating how many staff members at Durham are in fact themselves first-generation scholars. As Curtis Holder argues in the context of the United States, one approach to building inclusivity is 'to harness the experiences of faculty and staff members who come from similar backgrounds themselves. Even simple acts, such as adding social class to inclusivity and diversity statements, can be powerful' (2017: 658).

However, our respondents also wanted better support during their degrees. Many of their suggestions were relatively simple fixes such as ensuring students are informed about the basics at university and asking lecturers to refrain from using 'academic jargon' in the first few weeks. Some participants also suggested sessions for their parents on how best to support their children at university. Others highlighted how important it is to have connections with students from similar backgrounds, and cited recently launched First-Generation Scholars groups in the University as safe spaces that allowed them to engage academically and socially (Engstrom and Tinto 2008)

New targets for diversifying student intake will go some way to help meet these goals. However, the findings from our research are clear: inclusion remains a serious issue for highly selective universities not only because of barriers to admission but also because of student experiences during their studies. If universities are to meet the ambitious targets of the Office for Students in terms of access and attainment, inclusion will need to be mainstreamed throughout all aspects of the student experience. Making 'the playing field even' is an enormous challenge and working against long histories of inequality is an even greater one, but it is one that universities must rise to if they truly wish to benefit from the diversity of their student communities. As such it is an endeavour that is ultimately likely to benefit all students, not only those who are the first in their family to attend university. 


\section{Acknowledgements}

The project was funded by Durham University through an Enhancing Student Learning Award and ethical approval was provided by the ethics committee of Durham University Anthropology Department. We are grateful for the contributions of the students who participated in interviews for this project. We also acknowledge Prof Alan Houston, PVC for Education at Durham, and his support for this piece of research and the wider project of which it is part. Finally, we would also like to thank the many colleagues in our institution in academic departments and colleges, and the student population who are committed to making Durham a more inclusive University and who have provided inspiration and encouragement for this project.

Caitlin Hindle is an independent scholar who graduated from with an undergraduate degree in Anthropology at Durham in 2018. She is now employed as an engineer for Nissan, but retains a strong interest in issues around inclusion in higher education.

E-mail: caitlin.hindle@hotmail.co.uk

Vikki Boliver is Professor of Sociology at Durham University. Vikki's current research focuses on social inequalities of access to higher status universities, and on patterns and processes of social mobility across multiple generations. E-mail: vikki.boliver@durham.ac.uk

Ann Maclarnon is Master of Hatfield College at Durham University and Professor of Evolutionary Anthropology at Durham. As Master, Ann is responsible for leading all aspects of college life, including ensuring an excellent student experience and academic engagement. Ann's research interests include physiological adaptations of primates and the evolution of human speech.

E-mail: ann.m.maclarnon@durham.ac.uk

Cheryl McEwan is Professor of Geography at Durham University. Her research interests are focused around the intersections between cultural, political, and development geographies. At a conceptual level, her work has sought to explore the productive tensions between postcolonial and other radical approaches within geography. These theoretical concerns are also grounded in empirical research in South Africa and the UK. E-mail: cheryl.mcewan@durham.ac.uk 
Bob Simpson is Professor of Anthropology at Durham University. He is a social anthropologist whose research interests focus broadly on Bioethics, Biomedicine and Biotechnologies. He has also written numerous articles and essays on pedagogy and anthropology.

E-mail: robert.simpson@durham.ac.uk

Hannah Brown (corresponding author) is Associate Professor of Anthropology at Durham University. She has worked extensively in sub-Saharan Africa, where her research has focused on how people care for one another through institutions and interpersonal relations, particularly in the context of epidemics. With Vikki Boliver, she is the founder of the First Generation Scholars network at Durham University. E-mail: hannah.brown@durham.ac.uk

\section{Notes}

1. The term 'first-generation scholar' is widely used in the United States, where it often stands in for students from minority ethnic backgrounds, but it is much less used in the UK, where the literature tends to focus on working-class students and access to higher education. In our research, we chose to use the term 'first-generation scholars' because this term carries positive connotations rather than a 'negative' or potentially stigmatised characteristic (e.g., poverty). The term also incorporates a range of other student identities, encompassing students from lower income and 'working-class' homes as well as those from Black, Asian, and Minority Ethnic backgrounds, and it is less politically charged than other kinds of identifiers, such as 'working class'. Because it is a relatively broad category, it can potentially be expanded to include immigrants, or children of immigrants who may have experience of higher education in other settings but are in the 'first generation' of their family to experience a University education in the UK.

2. The OfS allocates students to neighbourhoods based on their postcode. Those students whose postcode falls within wards with the lowest participation (quintile 1) are denoted as being from a low participation neighbourhood.

3. Five of the students received the Durham Grant ( $£ 2000)$, one student also received a St. Nicholas Scholarship to support local students, and another had done a foundation year. Two students came to the university via the Supported Progression Scheme for local students and one student via the Sutton Trust Summer School.

4. Durham University, 'Sport', https://www.dur.ac.uk/experience/sport/ (accessed May 2020).

5. Castle JCR, 'Formals', https://castlejcr.com/formals/ (accessed 8 May 2021).

6. Such groups may also be sites of resistance on the margins that can effect radical change at the centre (hooks 1984), and as such, an important resource in challenging and changing problematic university cultures. 
7. Which?, 'Student budget calculator: Durham University', https://www.which.co.uk/ money/university-and-student-finance/student-budget-calculator/durham-university (accessed May 2020).

8. Gov.uk, 'Student finance', https://www.gov.uk/student-finance/new-fulltime-students (accessed May 2020).

9. The Supported Progression programme is offered to students within fifty miles of Durham City from areas with low rates of progression to university. The bursary offered is up to $£ 2000$ for each year of university attendance.

10. The Universities and Colleges Admissions Service (UCAS) is a UK-based organisation whose main role is to operate the application process for British universities. All students applying to higher education submit applications, including personal statements, to UCAS. The applications are then passed onto university admissions services.

11. The terms of application to this fund at Durham have since changed and the money is now offered as a non-repayable grant.

\section{References}

Allatt, P. (1996), 'Consuming schooling: Choice, commodity, gift and systems of exchange', in S. Edwell, K. Hetherington and A. Warde (eds), Consumption Matters (Oxford: Blackwell), 163-182.

Archer, L. and M. Hutchings (2001), “"Bettering Yourself”? Discourses of risk, cost and benefit in ethnically diverse, young working-class non-participants' constructions of higher education', British Journal of Sociology of Education 22, no. 4: 555-575. https://doi.org/10.1080/713655373.

Bills, D. B. (2003), 'Credentials, signals, and screens: Explaining the relationship between schooling and job assignment', Review of Educational Research 73, no. 4: 441-469. https://doi.org/10.3102/00346543073004441.

Boliver, V. (2015) 'Lies, damned lies, and statistics on widening access to Russell Group universities', Radical Statistics 113: 29-38.

Boliver, V., S. Gorard and N. Siddiqui (2021), 'Using contextual data to widen access to higher education', Perspectives: Policy and Practice in Higher Education 25, no. 1: 7-13. https://doi.org/10.1080/13603108.2019.1678076.

Boliver, V., M. Powell and T. Moreira (2018), 'Organisational identity as a barrier to widening access in Scottish Universities', Social Sciences 7, no. 9: article 151. https://doi.org/ 10.3390/socsci7090151.

Bourdieu, P. (1986), 'The forms of capital', in J. Richardson (ed.), Handbook of Theory and Research for the Sociology of Education (New York: Greenwood Press), 241-258.

Braun, V. and V. Clarke (2006), 'Using thematic analysis in psychology', Qualitative Research in Psychology 3, no. 1: 77-101. https://doi.org/10.1191/1478088706qp063oa. 
Byrom, T. and N. Lightfoot (2012), 'Transformation or transgression? Institutional habitus and working class student identity', Journal of Social Sciences 8, no. 2: 126-134. https://doi.org/10.3844/jssp.2012.126.134.

Chatelain, M. (2018), 'We must help first-generation students master academe's "hidden curriculum"', The Chronicle of Higher Education, 21 October, https://www.chronicle.com/ article/We-Must-Help-First-Generation/244830 (accessed June 2020).

Choy, S. (2001), Students Whose Parents Did Not Go to College: Postsecondary Access, Persistence, and Attainment (Washington, DC: National Center for Education Statistics).

Collier, P. J. and D. L. Morgan (2008), “'Is that paper really due today?”: Differences in first-generation and traditional college students' understandings of faculty expectations', Higher Education 55, no. 4: 425-446. https://doi.org/10.1007/ s10734-007-9065-5.

Crawford, C. (2014), Socio-economic Differences in University Outcomes in the UK: DropOut, Degree Completion and Degree Class, IFS Working Paper W14/31: Nuffield Foundation.

Curtis, S. and N. Shani (2009), 'The effect of taking paid employment during term-time on students' academic studies', Journal of Further and Higher Education 26, no. 2: 129-138. https://doi.org/10.1080/03098770220129406.

Department of Education (2018). 'Widening participation in higher education, England, 2016/17 age cohort-Official statistics', https://assets.publishing.service.gov.uk/ government/uploads/system/uploads/attachment_data/file/757897/WP2018 -MainText.pdf (accessed 25 January 2021).

Engstrom, C. and V. Tinto (2008), 'Access without support is not opportunity', Change: The Magazine of Higher Learning 40, no. 1: 46-50. https://doi.org/10.3200/ CHNG.40.1.46-50.

Harrison, N. (2018), 'Using the lens of "possible selves” to explore access to higher education: A new conceptual model for practice, policy, and research', Social Sciences 7, no. 10: 209-230. https://doi.org/10.3390/socsci7100209.

Henderson, M., D. Shure and A. Adamecz-Volgyi (2019), 'First in Family' University Graduates in England (Bonn: IZA Discussion Papers).

HESA (Higher Education Statistics Agency) (2018a), Higher Education Student Statistics: UK 2016/17, https://www.hesa.ac.uk/news/11-01-2018/sfr247-higher-educationstudent-statistics (accessed 28 September 2018).

HESA (Higher Education Statistics Agency) (2018b), Widening Participation: UK Performance Indicators 2016/17, https://www.hesa.ac.uk/news/01-02-2018/ widening-participation-tables (accessed 25 November 2018).

Hochstein, S. K. and R. R. Butler (1983), 'The effects of the composition of a financial aids package on student retention', Journal of Student Financial Aid 13, no. 1: 21-26. https://ir.library.louisville.edu/jsfa/vol13/iss1/3.

Holder, C. D. (2017), 'Coping with class in science', Science 355, no. 6325: 658. https:// doi.org/10.1126/science.355.6325.658. 
hooks, bell (1984), Feminist Theory: From Margin to Centre (London: Pluto Press).

Hordósy, R. and T. Clark (2018), 'Student budgets and widening participation: Comparative experiences of finance in low and higher income undergraduates at a northern red brick university', Social Policy \& Administration 53, no. 5: 761-775. https://doi.org/ 10.1111/spol.12410.

Inkelas, K. K, Z. E. Daver, K. E. Vogt and J. B. Leonard (2007), 'Living-learning programs and first-generation college students' academic and social transition to college', Research in Higher Education 48, no. 4: 403-434. https://doi.org/10.1007/ s11162-006-9031-6.

Ishitani, T. T. (2003), 'A longitudinal approach to assessing attrition behaviour among firstgeneration students: Time-varying effects of pre-college characteristics', Research in Higher Education 44, no. 4: 433-449. https://doi.org/10.1023/A:1024284932709.

Ishitani, T. T. (2006), 'Studying attrition and degree completion behaviour among firstgeneration college students in the United States', The Journal of Higher Education 77, no. 5: 861-885. https://doi.org/10.1080/00221546.2006.11778947.

Monaghan, M. (2018), 'Participation grant helps disadvantaged students get involved', The Student Newspaper, 1 November.

Murphy, C. G. and T. Hicks (2006), 'Academic characteristics among first-generation and non-first-generation college students', Faculty Working Papers from the School of Education 8, no. 1: 1-16.

National Center for Education Statistics (2002), Descriptive Summary of 1995-1996 Beginning Postsecondary Students: Six Years Later (Washington, DC: U.S. Department of Education).

Nettles, M. T. (1991), 'Racial similarities and differences in the predictors of college student achievement', in W. R. Allen, E. G. Epps and N. Z. Haniff (eds), College in Black and White: African-American Students in Predominantly White and in Historically Black Public Universities (Albany: State University of New York Press), 75-94.

NUS (National Union of Students) (2013), NUS Figures Show New Students Face Cost of Living Crisis. London: National Union of Students, https://www.nus.org.uk/ en/news/press-releases/nus-figures-show-new-students-face-cost-of-living-crisis/ (accessed 27 November 2018).

OfS (Office for Students) (2018), A New Approach to Regulating Access and Participation in English Higher Education Consultation Outcomes, https://www.officeforstudents .org.uk/media/546d1a52-5ba7-4d70-8ce7-c7a936aa3997/ofs2018_53.pdf (accessed May 2020).

Parveen, N. (2020), 'Students from northern England facing "toxic attitude” at Durham University', The Guardian, 19 October, https://www.theguardian.com/education/2020/ oct/19/students-from-northern-england-facing-toxic-attitude-at-durham-university. 
Pascarella, E. T., C. T. Pierson, G. C. Wolniak and P. T. Terenzini (2004), 'First-generation college students: Additional evidence on college experience outcomes', The Journal of Higher Education 75, no. 3: 249-284. https://doi.org/10.1080/00221546.2004 .11772256 .

Pike, G. R. and G. D. Kuh (2005), 'First- and second-generation college students: A comparison of their engagement and intellectual development', The Journal of Higher Education 76, no. 3: 276-300. https://doi.org/10.1080/00221546.2005.11772283.

Reay, D., G. Crozier and J. Clayton (2010), “Fitting in” or "standing out”: Working-class students in UK higher education', British Educational Research Journal 36, no. 1: 107-124. https://doi.org/10.1080/01411920902878925.

Reay, D., M. E. David and S. Ball (2005), Degrees of Choice: Social Class, Race and Gender in Higher Education (London: Institute of Education Press).

Reed-Danahay, D. (2005), Locating Bourdieu, 4th ed. (Bloomington: Indiana University Press).

Sutton Trust (2000), Entry to Leading Universities (London: Sutton Trust).

Sutton Trust (2007), University Admissions by Individual Schools (London: Sutton Trust).

Terenzini, P. T., L. Springer, P. M. Yaeger, E. T. Pascarella and A. Nora (1996), 'Firstgeneration college students: Characteristics, experiences, and cognitive development', Research in Higher Education 37, no. 1: 1-22. https://doi.org/10.1007/BF01680039.

Thayer, P. B. (2000), 'Retention of students from first generation and low income backgrounds', Opportunity Outlook 1, no. 1: 2-8.

Tinto, V. (1987), Leaving College: Rethinking the Causes and Cures of Student Attrition (Chicago: University of Chicago Press).

University of Durham (2019), Access and Participation Plan 2020/21 to 2024/25, https:// www.dur.ac.uk/resources/about/access/UniversityOfDurham_APP_2020-21_ V1_10007143.pdf (accessed May 2020). 